\title{
Research on Power Supply Service Under New Urbanization and Beautiful Countriside Construction
}

\author{
Si Liu, Minxiang Huang \\ College of Electrical Engineering, Zhejiang University, \\ Hangzhou, China \\ candyls@zju.edu.cn
}

\author{
Xuhua Fu, Lei Wang, Chengjin Ye \\ Economic Research Institute, State Grid Zhejiang \\ Electric Power Corporation, Hangzhou, China
}

\begin{abstract}
With the promotion of the new urbanization and beautiful countryside macro policy in China, the development of the rural power grid is driven fast. Rural customers have higher expectations of power supply service, and they pay more attention to service experience and efficiency. Under the new urbanization and beautiful countryside construction, based on the analysis of the demand and situation of the rural power supply service, this paper proposes responsible advice on service targets, thoughts and systems, which is meaningful for the promotion of power supply service.
\end{abstract}

Keywords-power supply service; new urbanization; power supply service system; rural network

\section{INTRODUCTION}

With the promotion of the new urbanization and beautiful countryside macro policy in China, and the integrative development of urbanization, industrialization, information technology and agricultural modernization [1]-[3], as well as the widely use of communication networking products, series of new requirements are made for rural power grid construction and power supply service. With the acceleration of urban-rural integration, the gap of power demand between urban and rural areas will narrow furtherly [4], customer demand for power supply service develops towards the diversified, personalized and interactive direction. Also, they have higher requirements and expectations of power supply service [5], and pay more attention to service experience and efficiency.

The goals, concepts, thoughts and modes of traditional rural power supply service can't meet the need under the new urbanization and the beautiful countryside construction. However, the current rural power grid construction emphasizes upgrading and reconstruction of technical equipment and operation levels, aiming at improving power supply quality and operating reliability. The lack of scientific analysis and deep thinking through the need and the development modes of power supply services in the new situation is a great limitation.

Combined with the new urbanization and the beautiful countryside macroeconomic policies, based on the demand and circumstance analysis of rural power supply service, this paper proposes the targets, thoughts and systems adapted to the new situation, broadening thoughts and laying the foundation of rural power supply service development.

\section{DEMAND AND CiRCUMSTANCES ANALYSiS}

\section{A. Demand Analysis}

1) The local government's development strategy puts foward new demand for power supply service.

As a leading role of the new urbanization and beautiful countryside construction, the government attaches great importance to it and establishes the new urbanization development mode with Chinese characteristics, raising higher requirements for infrastructure especially for power supply and guarantee [6]

First, with the development of the new urbanization and beautiful countryside construction, rural areas in conventional sense are experiencing fundamental changes, and a county with multiple towns or multiple small cities has formed. For the sake of the coordinated development of urban and rural economy, we should make power grid planning adapted to the new situation, as well as coordinate the planning and the development of urban and rural power grid as a whole [7].

Second, with the establishment of "three sets of five major" system in the state grid, and the completion of "BigCentralized Control" mode for substations, management becomes more professional and division of labor becomes more detailed. It's necessary to optimize the existing power supply service network to achieve the resource integration of power supply service [8]. With the deepening of the new urbanization and the beautiful countryside construction, the local government hopes that power substations can simplify work processes furtherly and offer "one-stop" service.

Third, with the promotion of township industrial parks construction, and the prosperity of township enterprises, as well as the promotion of "coal to electricity" reform projects, it's the social responsibility of power supply enterprises to reform the infrastructure, guarantee the power demand of township enterprises, projects and residents, as well as solve "low voltage" problem in rural power network areas around government strategies.

2) The economic and social development in rural areas puts forward new demand for power supply service.

With the promotion of urbanization and the rapid economic development in rural areas, traditional "villagers" are gradually turning to "citizens", and they expect higherquality power supply service. It's essential to adjust service contents immediately to adapt to the new situation, so as to satisfy the demand of rural areas development. 
First, we need to establish a unified power supply service system including management, service specification, codes of conduct, supervision system and brand image promotion. Also it's necessary to build an urban-rural integrated power supply service supporting platform which unifies specific requirements in urban and rural areas, fully implement standardized power supply service by improving quality standards and basic norms as well as unifying service channels, items and behaviors.

Second, combining local economic and social conditions and regional characteristics, there is a must to optimize and accelerate the business expansion processes, as well as carry out customer-oriented and personalized service in order to increase customer satisfaction. Based on customer groups subdivision, we need to propose individual and differentiated service fit for all types of customers.

Third, due to long power lines, wide ranges and complex situations in rural areas, there are many unsafe factors that may affect power supply. With the fast increase in the rural power demand, rural customers are in urgent need of scientific and safe power utilization. Therefore we need to take effective measures to ensure safe power supply.

3) The rapid development of new businesses puts forward power supply service.

With the widely use of distributed energy resources, we need to establish suitable service system to guarantee the demand of new businesses on the premise of power utilization security.

First, adjust the service mechanisms and optimize the business processes to make adequate preparations for new energy accommodation.

Second, strengthen publicity for electric power alteration strategy, and promote the use of energy-saving products and technologies to build clean homes.

Third, with the popularization of the Internet and information products, it becomes a new trend to create an intelligent and interactive service system based on platforms such as websites, twitters and blogs where electricity bill inquiry, customer complaints and online business are available, making power supply service more convenient, efficient and interactive.

\section{B. Circumstances Analysis}

1) The rural power management faces new challenges.

Due to institutional and mechanisms barriers, rural power development is still deficient. It's difficult to deliver professional management concept to primary power substations. Facing the new situation and new tasks of rural power supply service, we should establish customer-oriented and problem-oriented service systems to eliminate shortcomings. Moreover, there is a need to promote standardized and specified management, with horizontal coordinating in competent authorities and vertical managing in particular sectors, so as to form a work pattern of joint management.

\section{2) Rural service faces new challenges.}

Though there's a rapid advance of rural power grid construction, in some areas, especially in remote mountainous and economically backward areas, where their distribution networks are still weak, power supply especially in peak periods is insufficient. The insulation level is low, and the ability to resist natural disasters is weak, the imbalance between customer demand and supply still exists in a certain period. Because of the variation of geographical, economic and cultural environment in rural areas, customer demands vary widely. It's required to establish power supply service mechanisms adapted to the new situation, and to improve power supply capacities and service qualities.

3) The rural power team faces new challenges.

Rural power supply service quality is a direct result of staff quality. In a case of a provincial electric power corporation, there are 20664 rural staffs in all covering urban and rural electric power companies, occupying $88.6 \%$ of the required capacity. Rural staffs' age, educational background and job titles structure are shown in table I.

\section{TABLE I. RURAL STAFF' AGE, EDUCATIONAL BACKGROUND AND PROFESSIONAL TITLES STRUCTURE}

\begin{tabular}{|c|c|c|c|}
\hline \multirow{2}{*}{ Age } & $\geq 50$ & Number & Percentage \\
\cline { 2 - 4 } & $40 \leq a g e<50$ & 5231 & $25.30 \%$ \\
\cline { 2 - 4 } & $30 \leq a g e<40$ & 7175 & $34.80 \%$ \\
\cline { 2 - 4 } & $<30$ & 2399 & $11.60 \%$ \\
\hline $\begin{array}{c}\text { Education } \\
\text { Background } \\
\text { and } \\
\text { Professional } \\
\text { Titles }\end{array}$ & $\begin{array}{c}\text { Junior college degree or } \\
\text { above }\end{array}$ & 7781 & $37.70 \%$ \\
\cline { 2 - 4 } & Senior title or above & 8464 & $41 \%$ \\
\cline { 2 - 4 } & Junior title or above & 732 & $3.60 \%$ \\
\hline
\end{tabular}

We can conclude from table I, on the one hand, because of the historical influences, the current staff allocation is still low-educated, aged and shorthanded, mismatching power supply service demand under the new urbanization and beautiful countryside construction. On the other hand, influenced by the labor institution, rural power staffs lack the sense of belongings and ownership as well as motivations and initiatives for jobs.

\section{SERVICE TARGETS, ThOUghtS AND Systems}

\section{A. Service Targets}

It is significant to implement the high-quality service concept which focuses on the customers and problems [9], take the new urbanization and the beautiful countryside construction as the starting point, and then take lean management, standardized service, informationized platform, diversified carrier and elite team construction as targets. We should spare no efforts to find and eliminate customers' dissatisfaction points [10], try our best to enhance customers' satisfaction by improving service abilities and levels, standardizing service processes and innovating service measures, so as to build a responsive, specified, sincere and customer-satisfied rural power supply service system, laying a solid foundation for the new urbanization and beautiful countryside construction. 


\section{1) Lean management construction.}

Insisting on the intensive, flat and professional direction, we should continue to promote management improvement projects, and strengthen the internal coordination as well. Furthermore, in order to achieve the institution and staff optimization, it's crucial to promote the standardized management and clearly define the business division, then adjust business processes and strengthen the core business controlling so as to improve the professional management levels constantly.

\section{2) Standardized service construction.}

On the basis of the existing measures and strategies implemented by power supply enterprises, there is a need to optimize service interfaces and set both comprehensive and effective service standards. Initially, we need to analyze customers' expectations for power supply services to grasp their core demands accurately. Then by quantifying enforcement costs, it's necessary to propose sustainable service commitment standards and track customers' behaviors so that we can grasp their demand changes and optimize service commitment standards dynamically.

3) Informationized platforms construction.

In order to promote the use of rural electricity service information management platforms and fully tap the potential of the existing platforms, we need to enhance the data homology management by integrating data from different systems so that we can realize service information synchronously updated and real-time interaction. Relying on new technologies and platforms, we should establish new service modes and explore new ways to improve customer experience in conditions of informatization.

\section{4) Diversified carrier construction.}

To establish a customer-oriented service system, it's required to improve the universal service mechanisms. Also, there's a need to offer special service for rural power supply, as well as adopt both diversified and personalized service measures to fully fulfill power supply service commitments.

\section{5) Elite team construction.}

With the purpose of providing high quality manpower resource support, we should strengthen cohesion and ability of rural power teams, and try our best to improve their service skills, implement initiative service consciousness, and properly settle the staff shortage.

\section{B. Service Thoughts}

Reaching the balance of service supply and demand is an important part of the new urbanization and beautiful countryside construction. To accomplish the target, it's necessary to refine service measures, enhance service awareness as well as enrich service contents oriented by customer demand.

1) Establish service mechanisms adapted to the new situation.

First, we should adjust service contents immediately based on rural economic and environmental changes, and optimizing service processes by advancing service sectors to improve service quality and efficiency. Second, we need to provide differentiated service to meet the diversified power demand. Third, it's a must to foster people-oriented and customer demand-oriented awareness, as well as provide humanized service so that we can create flexible service mechanisms.

2) Enhance service abilities adapted to the new situation.

First, we must carry out prospective research on the new urbanization and beautiful countryside construction, and enhance real-time communication and interaction with the government and customers as well so as to make scientific distribution grid planning in the balance of the power demand. Second, we should speed up to build the internal service chains, also strengthen internal coordination and cooperation to establish collaborative service systems. Third, it's needed to strengthen the research on new energy access and new technologies in order to make full preparations for service support and promote clean energy development.

3) Strengthen power supply service mechanisms construction.

First, we need to set up business-net spots reasonably as needed and improve service efficiency to reduce rural power supply service radiuses. Second, it' necessary to strengthen the planning of institutions to provide system guaranteed for power supply service. Second, we should strengthen professional team construction and improve service levels to ensure service quality. Also, there is a must to establish sound improved power supply service mechanisms to obtain continuous improvement and promotion. Third, to improve power supply service abilities, it's needed to accelerate applications of power supply service information system and promote intelligent and standard service.

\section{Service Systems}

The administration should spare no efforts to build the customer-oriented power supply service system, shown in Fig 1. It is workable to improve service quality and experience by strengthening internal coordination, optimizing workflow, enhancing efficiency, extending service measures and so on.

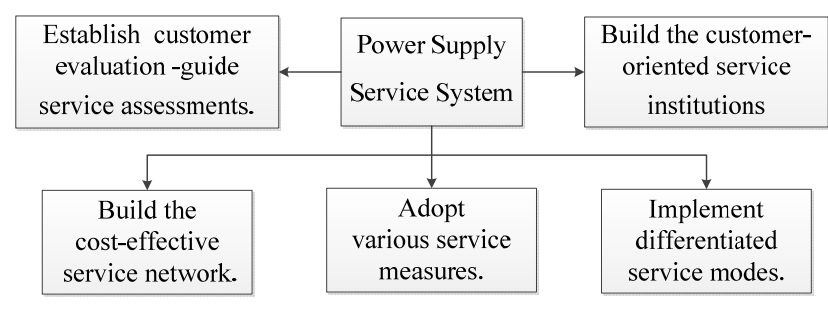

Figure 1. Power supply service system

1) Build the customer-oriented service institutions.

We should rationalize internal service mechanisms and integrate internal service resources, also we need to intensify service functions in the marketing foreground and support functions in the maintenance background. Moreover, according to market segments, it's essential to set up serviceoriented institutions designed for different market segments and different users. For instance, we can establish the big customer service department in industrial towns to provide 
the on-site service and the energy-saving advice. Then, we need to accentuate assessment in the marketing foreground, and establish evaluation index system aiming at crucial aspects such as business expanding, power accessing and fault clearing, also decompose evaluation process into foreground and background to ensure assessment quality.

2) Implement differentiated service modes.

There is a need to subdivide customer groups furtherly, and refine the existing service mode mainly by improving humanized service content for different customer groups. Also, we can promote the customer-manager system to provide specific service based on customer characteristics. For example, we can assign customer managers for VIPs, key businesses and government agencies, while assign community managers in charge of meter-reading, costs charging and consulting in rural communities. As well, it is need to simplify and standardize the business processes, and assign responsibilities to the people so as to achieve "onestop" customer service. We should hold the concept of preeminent and active service, make full use of localization service and take the initiative to coordinate and solve various problems existed in power consumption.

3) Adopt various service measures.

After fully understanding customer needs, there is need to provide on-site and door-to-door service which can narrow the distance with customers. Also, we should establish mobile service mechanisms offering on-site service items such as fault diagnosis. Then we can take advantages of diversified channels and the third-party platforms, such as business lobby, Internet and mobile terminals to provide onestop and all-day service, where electric quantity and bill inquiring, power-off notice are available. Moreover, we need to extend payment methods with comprehensive utilizations of pre-paid cards and mobile terminals to achieve the humanized service target.

4) Build the cost-effective service network.

It's necessary to optimize the existing service network construction, refine payment channels and communication modes based on the observations of customer behaviors, and provide cost-effective service solutions. There is a must to construct overall customer service network covering power repairing, customer service, business expanding, meter measuring, and energy efficiency management on the basis of specific customers division. Also we should optimize the layout of service outlets in accordance with administrative division adjustment, and on the cost-effective principle, it's better to adopt the "power substations with service stations" mode according to local conditions.

5) Establish the customer evaluation-guide service assessments.

It's of great importance to improve power supply service customer evaluation system. On the one hand, we should Sufficiently listen to the feedbacks from customers and enterprises, keep track of customer satisfaction surveys, and strengthen complaints analysis and assessment systems. Then, we need to analyze causes of complaints and look up defects in the service. On the one hand, there is a must to strengthen external oversight and hire supervisors to get regular feedbacks, as well as strengthen internal oversight, so that to establish power supply service quality supervision mechanisms to discover and solve problems timely.

\section{CONCLUSIONS}

The new urbanization and beautiful countryside macro policy drives the fast development of rural power grid. With the acceleration of urban-rural integration, rural customers have higher expectations of power supply service, which is diversified, personalized and interactive.

Through the demand and circumstance analysis of rural power supply service, the imbalance of demand and supply is quite evident and will exist in a certain period for it's a result of many complex factors.

What's more, this paper gives reasonable and practical advice on rural power service construction, by establishing service mechanisms adapted to the new situation, and taking various measures to strengthen service abilities, we can build the customer-oriented power supply service system as well as foster an elite staff team, so as to achieve the balance of customer demand and supply and realize the coordinated development of urban and rural areas eventually.

\section{REFERENCES}

[1] Development Research Center of the State Council, New Urbanization of China: Method, Model and Policy. Beijing: China Development Press, 2014

[2] Wang Li, Zhou Aimin. New Urbanization: A New Power of Rural Power Network Development. China Power Enterprise Management. 2014,24: 18-23

[3] Shan Zhuoran, Huang Yaping. An Analysis of the concept, Goals, Contents, Planning Strategies and Misunderstandings of New Urbanization. Urban Planning Forum,2013,02:16-22

[4] He Chunguang, Wang Tao, Dong Xin. Corelation Analysis Method on Total Electricity Consumption and Urbanization Rate and Its Application. Hebei Electric Power, 2014,03:19-22

[5] Huang Li, Wei Zhinong, Wei Yanfang, Sun Guoqiang, Sun Yonghui, Liu Jinsong. A Survey on Interactive System and Operation Patterns of Intelligent Power Utilization. Power System Technology,2013,08: 2230-2237

[6] Qiu Weijie. Research on Operation Law of Electric Economy in China. Ph D Thesis. Nanjing: Nanjing University of Aeronautics and Astronautics, 2006

[7] Zhang Yu, Su Jianhua. The Existing Problems and Solutions to Rural Power Production Safety. Rural Electician,2006,02:5

[8] Zhang Caiqin, Xie Ping, Wang Ting. China Electric Power(Technology Edition),2011,07:1-4

[9] Xie Binen. Construction of "customer-oriented" value creation system. China Power Enterprise Management,2013,11:74-75

[10] Zhuang Linghu. Power customer service of social responsibility Thinking. China Electric Power Education,2013,17:178-179. 